\title{
Hot Ductility of a Microalloyed Steel in the Intermediate Temperature Range
}

\author{
A. Darsouni, B. Bouzabata and F. Montheillet* \\ Unity of Research in Metallurgy and Materials, University of Annaba, Algérie \\ * Microstructure and Processing Laboratory, URA 1884 du CNRS, S.M.S., Ecole Nationale Supérieure \\ des Mines de Saint Etienne, 42023 Saint-Etienne, France
}

\begin{abstract}
In this study hot ductility has been determined from tensile tests for two states of a microalloyed steel: after casting and after rolling processes. Hot deformations were carried out at speeds varying from $10^{-4} \mathrm{~s}^{-1}$ to $10^{-2} \mathrm{~s}^{-1}$ and temperatures from $750^{\circ} \mathrm{C}$ to $1100^{\circ} \mathrm{C}$. Two heat treatments were chosen before hot deformation. A ferrite precipitation is observed at austenitic grain boundaries in the intercritical temperature range, causing intergranular embrittlement. Ductility trough is deeper in the as-cast samples due to the growth of large grain size. Also, precipitation makes the hot ductility curve wider and deeper around $900^{\circ} \mathrm{C}$. The results show a decrease in hot ductility. Minimum values of hot ductility are determined for (ITC) treatment at $900^{\circ} \mathrm{C}$ and for (DTC) treatment at $800^{\circ} \mathrm{C}$. For this second treatment another decrease in hot ductility was observed at $900^{\circ} \mathrm{C}$. We can explain hot ductility losses by the presence of precipitates in the austenitic region and the presence of the two-phase structure in the intercritical region.
\end{abstract}

\section{INTRODUCTION.}

The elaboration and hot processing of metals are usually restricted by the occurrence of defects, generating a ductility fall, wich can compromise their further use. These defects take the appearance of superficial or internal cracks. For some materials, it has been noted a temperature range were ductility is low, due to hot brittleness. For industrials, the understanding of the various mechanisms related to hot brittleness, as well as a perfect knowledge of this ductility trough, are required for the high temperature processing of steels, like forging, rolling or pressing.

In the case of very complex industrial steels, where various interactions between the elements are present, several effects are superposed during hot deformation, and particularly work hardening possibly followed by recovery, grain boundary sliding or migration associated with dynamic recrystallization.

In the austenitic region and for steels containing sulphur, brittleness type is intergranular and is related to the precipitation of mixed manganese and iron sulphides [1]. This occurs as a dispersion of small hardening precipitates inside the grains, or in the austenitic grain boundaries. In the $\alpha-\gamma$ two-phase region, there is usually a cumulative effect of a proeutectoid ferrite film present at grain boundaries and the precipitation of manganese sulphides in these boundaries, that causes the steel intergranular ductile fracture [2]. This mechanism is observed in steel during straining between $600^{\circ} \mathrm{C}$ and $1000^{\circ} \mathrm{C} \mathrm{[3].}$

The addition of elements such as $\mathrm{Mn}, \mathrm{Ti}, \mathrm{Nb}, \mathrm{V}$, and $\mathrm{Al}$, plays an important role in hot ductility. In fact, Mn induces the formation of low Mn content sulphides, with low melting point [4]. In niobium steels, combined influence of $\mathrm{Ti}$ and $\mathrm{Nb}$ allows to improve ductility because a combination forms between titanium nitrides and niobium carbonitrides precipitates in complex $\mathrm{TiNb}(\mathrm{CN})$ form [5]. These complexes seem to be less prejudicial than fine $\mathrm{Nb}(\mathrm{CN})$ precipitates. Moreover, in the presence of vanadium, hot ductility is also improved by a delay of $\mathrm{Nb}(\mathrm{CN})$ precipitation in steels [6].

So, it is thus the synergetic effect of TiN, AlN, NbCN, VCN and (Fe, Mn)S precipitation at grain boundaries [7], with the intergranular sulphur segregation at grain boundaries and at precipitate-matrix interfaces, that causes a decrease of intergranular cohesion.

Actually, precipitates are considered as potential sites for the nucleation of intergranular cavities. The dynamic recrystallization delay or the grain boundary migration slowing down due to the above mentioned precipitates, favour the nucleation of cavities during intergranular sliding.

Finally, between $600^{\circ} \mathrm{C}$ and $1000^{\circ} \mathrm{C}$, hot ductility depends on the thermal treatment type [8]. 
In this study, two microalloyed steels (C-Mn-S-Al-Ti-Nb-V) obtained either directly by casting or after hot rolling, were deformed between $700^{\circ} \mathrm{C}$ and $1100^{\circ} \mathrm{C}$ by tension at strain rates from $10^{4} \mathrm{~s}^{-1}$ to $10^{-2} \mathrm{~s}^{-1}$; after treatment by two types of annealing processes, an Increasing Temperature Cycle (I.T.C.), and a Decreasing Temperature Cycle (D.T.C.). Results show a decrease in hot ductility in which minima are located either at $900^{\circ} \mathrm{C}$ in the I.T.C. case, or at $800^{\circ} \mathrm{C}$ in the D.T.C. case. In this last treatment a second minimum is observed at $900^{\circ} \mathrm{C}$. These hot ductility losses can be explained by the presence of precipitates in the austenitic region and by the two-phase structure in the intercritical region.

\section{EXPERIMENTAL TECHNIQUES.}

The samples were taken either directly from a Rough Cast piece (R.C.), or from a Hot Rolled plate (H.R.). This microalloyed steel type or dispersoid steel was provided by the steel company SIDER-ELHADJAR.

The chemical compositions of these two types of specimen are shown in the following table:

\begin{tabular}{|c|c|c|c|c|c|c|c|c|c|c|c|}
\hline & $\% \mathrm{C}$ & $\% \mathrm{~S}$ & $\% \mathrm{P}$ & $\% \mathrm{Al}$ & $\% \mathrm{Si}$ & $\% \mathrm{Mn}$ & $\% \mathrm{~V}$ & $\% \mathrm{Nb}$ & $\% \mathrm{Ti}$ & $\% \mathrm{O} 2$ & $\% \mathrm{~N} 2$ \\
\hline B.C. & 0.044 & 0.0075 & 0.012 & 0.017 & 0.22 & 1.45 & 0.053 & 0.080 & 0.041 & 0.0015 & 0,006 \\
\hline H.R. & 0.075 & 0.011 & 0.017 & 0.047 & 0.22 & 1.67 & 0.051 & 0.062 & 0.045 & 0.0015 & 0,006 \\
\hline
\end{tabular}

Chemical composition of the R.C and H.R. specimens (wt \%).

The Ac1 and Ac3 transformation temperatures were determined by dilatometric analysis, giving respectively $710-850^{\circ} \mathrm{C}$ for the R.C. state and $705-855^{\circ} \mathrm{C}$ for the H.R. State.

Metallographic study of initial microstructures allowed to reveal that the R.C. grain size is much larger than the H.R. grain size. After heat treatment this grain size difference is lowered.

On these two series of specimens, two types of thermal treatment were carried out before deformation, after homogenization during one hour at $1300^{\circ} \mathrm{C}$ and water quenching. The first one is an Increasing Temperature Cycle (I.T.C.) (fig. 1), which aims to obtain a maximal precipitation of particles such as carbides, carbonitrides and nitrides before deformation. It consists of a $850^{\circ} \mathrm{C}$ annealing, during one hour, under argon followed by a slowly cooling in the furnace.

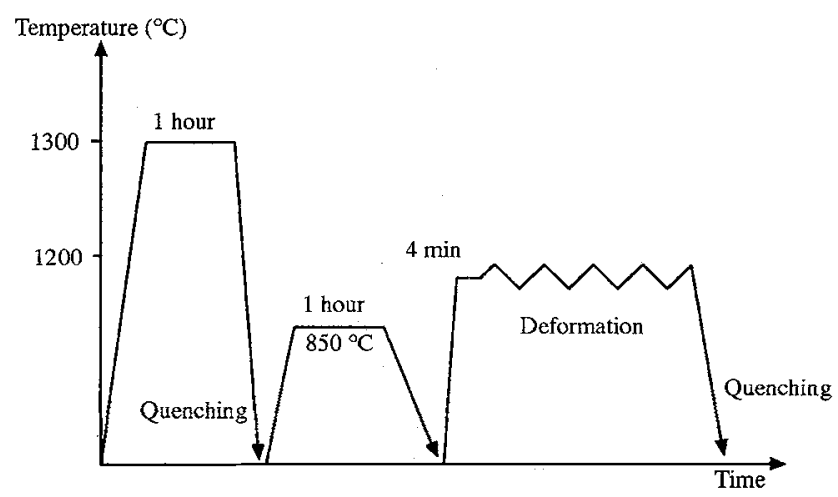

Figure 1: Increasing Temperature Cycle

The second treatment used is a Decreasing Temperature Cycle (D.T.C.) (fig 2). This one allows the precipitates dissolution thanks to a heating at $1200^{\circ} \mathrm{C}$ followed by a cooling down to the deformation temperature.

The hot tension device used allows the samples (with conic heads) to be fastly quenched after breaking. The tension tests were made under argon. The sample heating is obtained with an infra-red furnace which allows the treatment cycle to be programmed before deformation. 


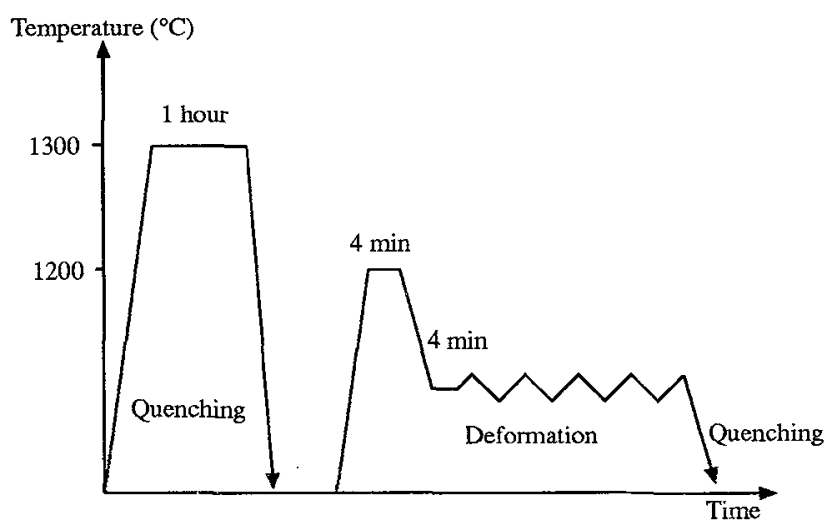

Figure 2: Decreasing Temperature Cycle

Ductility has been mesured through the $\Sigma \%$ coefficient, linked to the fracture area reduction by:

$$
\Sigma \%=\left(\frac{\mathrm{So}-\mathrm{Su}}{\mathrm{So}}\right) \cdot 100
$$

Metallographic observations on longitudinal sections of the quenched samples were made with a Scanning Electron Microscope, after ionic etching. Fracture surfaces of the non quenched parts were also observed with a S.E.M.

\section{RESULTS AND DISCUSSIONS.}

\subsection{Stress-strain curves.}

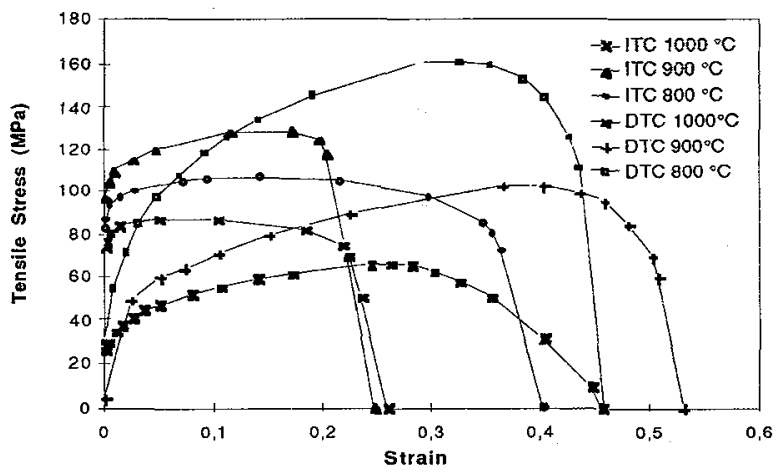

Figure 3: Rough Cast Steel.

$\sigma(\varepsilon)$ curves were obtained from the experimental load-deformation curves after substraction of the elastic strain. A typical example is shown in fig. 3 for the R.C. steel submitted to the I.T.C and D.T.C. treatments, and deformed at several temperatures.

The general aspect of the curves can be represented by a fast stress increase followed by a plateau, where peaks do not seem to be predominant. Such a behaviour is usually associated with a dynamic recovery occurring up to elevated temperatures. Nevertheless, at $1200^{\circ} \mathrm{C}$, the typical oscillating aspect associated with dynamic recrystallization can be observed. 
The influence of annealing on maximum stress is shown in fig. 4 for the R.C. steel. This behaviour is the same for the two series of specimens at any temperature and strain rate. In fact, the maximum stress is higher in the two-phase range for the D.T.C. treatment. But in the austenitic region the inverse is observed. These observations illustrate the hardening by solid solution, due to the D.T.C. treatment, in the $\alpha-\gamma$ region. Above $900^{\circ} \mathrm{C}$, this precipitate dissolution has little influence on the austenitic phase.

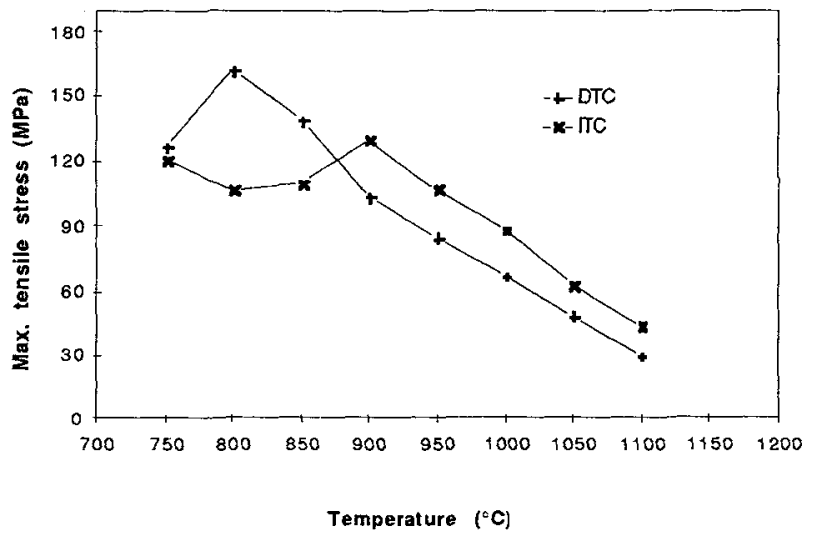

Figure 4: Rough Cast Steel

\subsection{Hot ductility.}

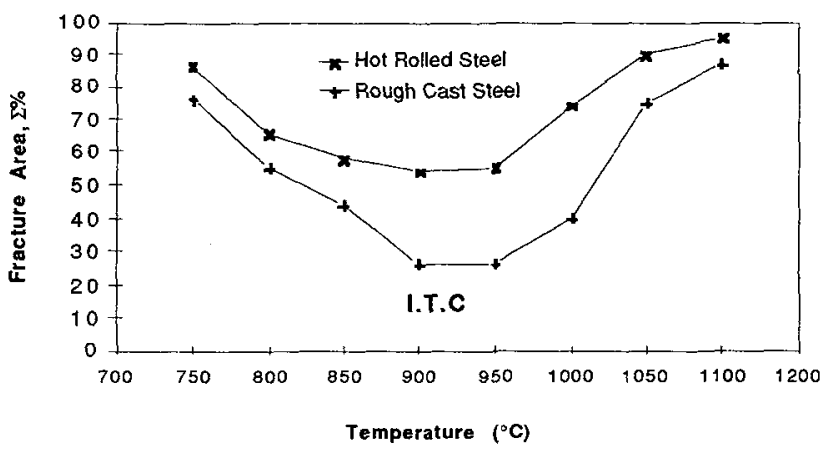

Figure 5: Fracture area-Temperature dependence

The temperature dependence of the $\Sigma \%$ ductility criterion, i.e. the fracture area reduction, is given in fig. 5 for the two series of specimens after I.T.C. and D.T.C. treatment, respectively. A ductility trough varying with the annealing cycle can be observed.

The metallographic study of the initial microstructure allowed to reveal that grain size in R.C. steel is much larger than in H.R. case. After heat treatments this grain size difference is lowered.

In the case of the D.T.C. treatment, involving a maximum dissolution of precipitates before deformation, the temperature dependence of ductility (fig. 6) is characterized by two minima. The first one occurs at $800^{\circ} \mathrm{C}$, in the $\alpha-\gamma$ domain. However, a second slight trough is seen in the $\gamma$ region at $900^{\circ} \mathrm{C}$. The brittleness mechanisms seem to be different since they are linked with the two-phase microstructure in the $\alpha-\gamma$ region, and to synergetic effects, i.e. precipitation and segregation in the austenitic phase. 
In the case of the $900^{\circ} \mathrm{C}$ ductility trough, before deformation, the $1200^{\circ} \mathrm{C}$ dissolution treatment causes the decomposition of the aluminium nitrides at the austenitic grain boundaries, thus enforcing the aluminium to remain in these boundaries. Then, its strongly alphagene character induces ferrite formation at the austenitic grain boundaries, at higher temperatures than those of the $\alpha-\gamma$ transformation.

In fact, at $800^{\circ} \mathrm{C}$, microstructural observations have shown the presence of primary ferrite located in the austenitic grain boundaries (fig. 7). In this region, the ductility loss grows with increasing temperature. Then, ductility varies directly with the grain boundary ferrite fraction, involving a localization of strain. When the test temperature is above $800^{\circ} \mathrm{C}$, a dynamic precipitation is generated inducing a ductility fall at $900^{\circ} \mathrm{C}$.

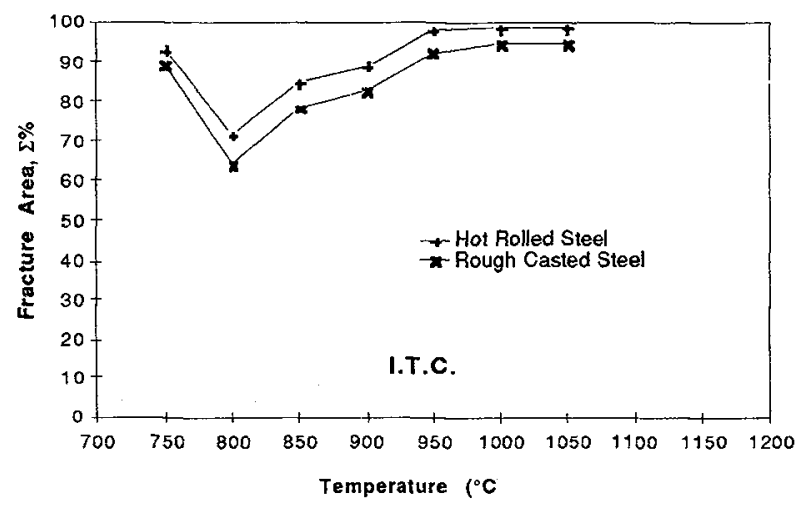

Figure 6: Fracture Area-Temperature dependence

In the case of I.T.C. treatment, the fall of ductility is pronounced, wider, and maximum at $950^{\circ} \mathrm{C}$. Near this temperature, precipitation increases because dynamic precipitation for $\mathrm{Nb}(\mathrm{CN})$ and $\mathrm{AlN}$ are maximum at $900^{\circ} \mathrm{C}$ and $885^{\circ} \mathrm{C}$, respectively [9]. Moreover, the I.T.C. cycle seems to favour the obtention of a finer and less ductile austenite.

At $900^{\circ} \mathrm{C}$, duplex precipitates of TiN and $\mathrm{MnS}$ are observed in the microcracks (fig. 8) and constitute the main cause of the decrease in ductility.

\subsection{Fracture surfaces.}

The microfractographic observations have shown that, in the decreasing ductility region, the type of fractures surfaces is ductile with dimples resulting in some cases into "cup and cone" fracture. In the dimples (fig. 9), MnS precipitates are associated with Al traces. At higher temperatures, rectangular precipitates were observed. Composition analysis shows that they are mixed precipitates of (TiN, MnS). The latter seem to be responsible for the decrease in ducility.

At $900^{\circ} \mathrm{C}$ in the D.T.C. case, the fracture surface is much disturbed, with a presence of TiN and MnS precipitates inside the river on the left (fig. 10).

\section{CONCLUSIONS.}

In the intercritical domain, brittleness mechanisms are linked with the two-phase microstructure. Usually, the cumulated effect of a ferrite film and precipitates at grain boundaries induces a ductile intergranular fracture.

In the austenitic range, precipitation and segregation synergetic effects cause the ductility loss.

The fracture surfaces show an important role of duplex type precipitates like titanium nitrides, manganese sulphides or mixed type particles such as $\mathrm{TiNb}(\mathrm{CN})$. 


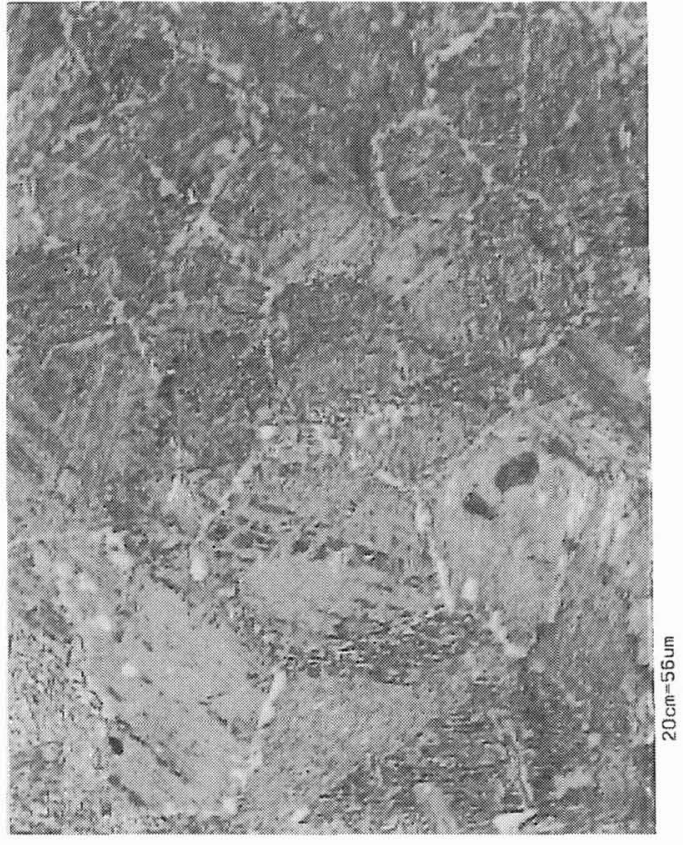

Figure 7: Hot Rolled- $800^{\circ}$ C-D.T.C.

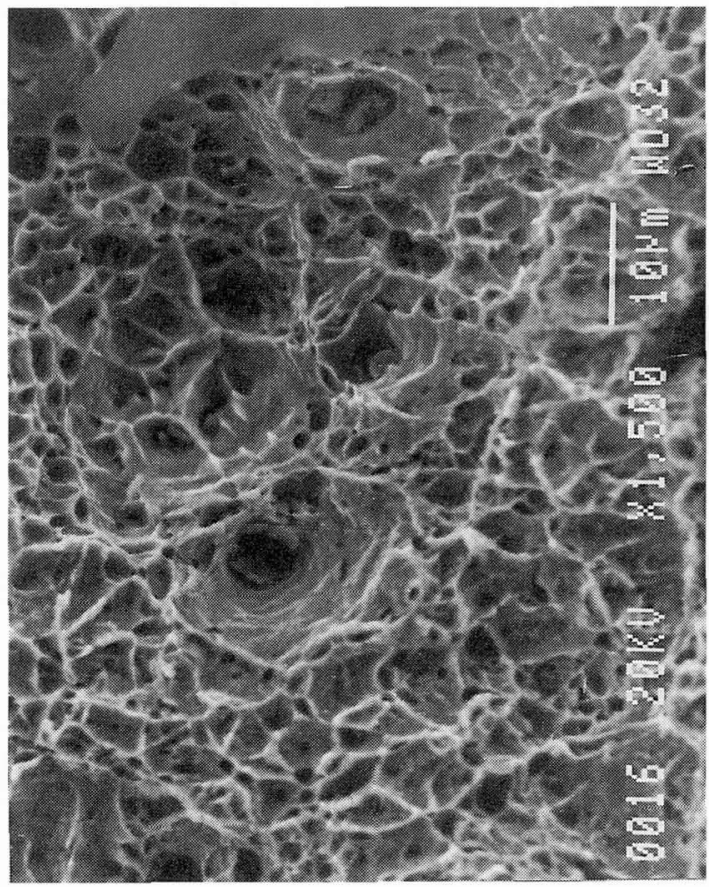

Figure 9: $800^{\circ}$ C-D.T.C. Aspect of the ductile fracture surface with dimples

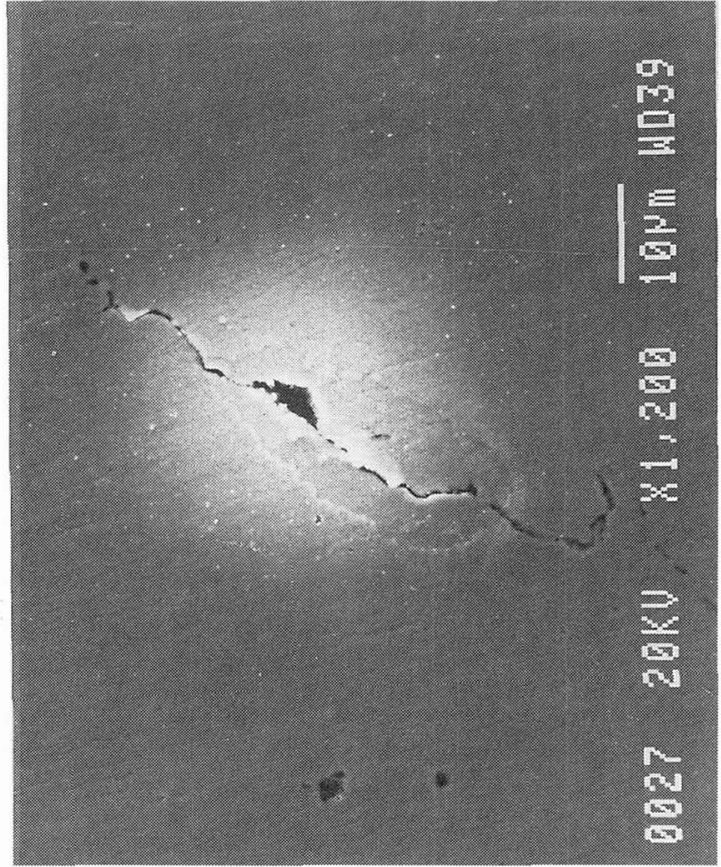

Figure 8: $900^{\circ} \mathrm{C}$-D.T.C. Quenched part longitudinal section. Microcrack presence near the fracture area with MnS and TiN precipitates inside (after ionic etching)

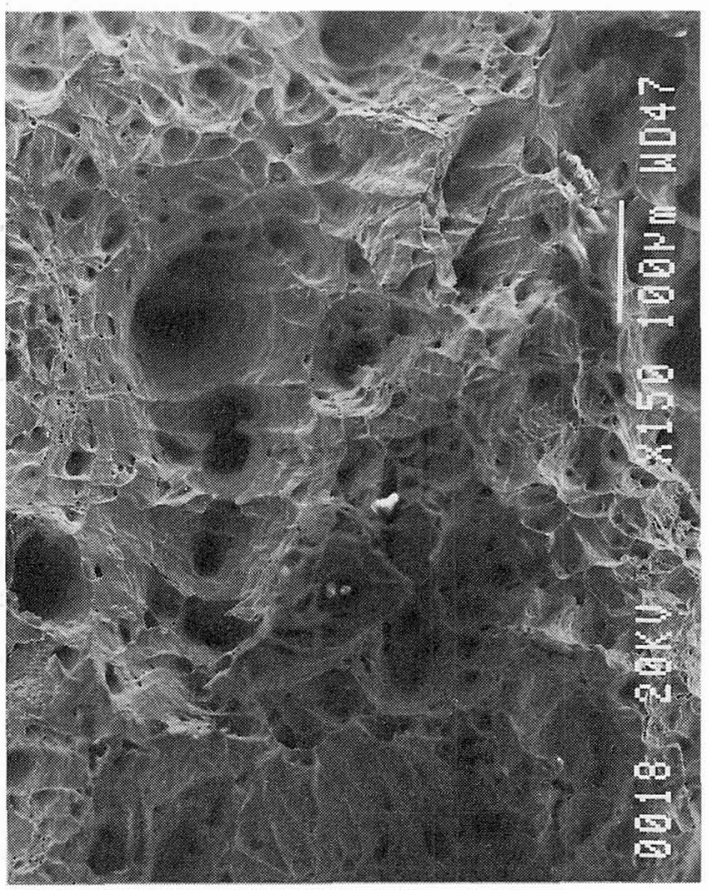

Figure 10: $900^{\circ} \mathrm{C}-$ I.T.C. Aspect of the ductile fracture surface dimples 


\section{REFERENCES .}

[1] K. Yasumoto, Y. Maehara, S. Ura and Y. Ohmuri, Mat. Sci. Technol., 1.111, (1985).

[2] K. Yamanka, F. Terasaki, H. Ohtani, M. Oda and M. Yoshihana, Trans. Iron Steel Inst., 20, 810, (1980).

[3] H.G. Suzuki, S. Nishimura and S. Yamaguchi, I.S.I.J. 22, 48, (1982).

[4] T. Wijadlowski, J.Y. Boos, P. Poyet and C. Goux, C.R. Acad. Sci. Paris, 276, 383, (1973).

[5] A. M. Guillet, Thèse Ph.D., Mc Gill University, Canada, (1989).

[6] H.G. Andrade, M.G. Akben and J.J. Jonas, Met. Trans. A, vol 14A, 1967, (1983).

[7] Y. Ping-Hua, Thèse de doctorat, E.N.S.M. Saint-Etienne, France, (1989).

[8] M. Tacikovski, Thèse de doctorat, E.N.S.M Saint-Etienne, France, (1986).

[9] J.P. Michel, M. Akben, J.J. Jonas, Rev. Met. CIT, (1981).

Acknowledgements- The authors are indebted to Mr. R. MOYA for his technical support. 